\title{
Erratum
}

\section{Refractoriness of aggressive behaviour to pharmacological treatment: cortical thickness analysis in autism spectrum disorder - ERRATUM}

Flavia Venetucci Gouveia, Jürgen Germann, Gabriel A. Devenyi, Rosa M. C. B. Morais, Ana Paula M. Santos, Erich T. Fonoff, Clement Hamani, Helena Brentani, M. Mallar Chakravarty and Raquel C. R. Martinez

\section{Keywords}

Autistic spectrum disorders; intellectual disability; neuroimaging; cortical thickness; aggressive behaviour; erratum.

\section{Copyright and usage}

(C) The Author(s), 2020. Published by Cambridge University Press on behalf of BJPsych Open. This is an Open Access article, distributed under the terms of the Creative Commons Attribution licence (http:// creativecommons.org/licenses/by/4.0/), which permits unrestricted re-use, distribution, and reproduction in any medium, provided the original work is properly cited.

https://doi.org/10.1192/bjo.2020.71, Published online by Cambridge University Press, 7 August 2020
This article fails to state the coequal contribution to the article of its first two authors, Flavia Venetucci Gouveia and Jürgen Germann. This note was deleted accidentally during the production process, for which the publisher apologises.

\section{Reference}

1 Gouveia FV, Germann J, Devenyi GA, Morais RMCB, Santos APM, Fonoff ET, Hamani C, Brentani H, Chakravarty MM and Martinez RCR. Refractoriness of aggressive behaviour to pharmacological treatment: cortical thickness analysis in autism spectrum disorder. BJPsych Open 2020; 6: e85. doi: 10.1192/ bjo.2020.71. 